\title{
Prevalence of partial edentulism among young Saudi women of Qassim and their perception of early tooth loss
}

\author{
Amal Almutairy ${ }^{1 *}$, Minu Mohan ${ }^{2}$ \\ ${ }^{1}$ Internship dentist, college of dentistry, Qassim university, Saudi Arabia \\ ${ }^{2}$ Assistant professor, Department of prosthetic dental sciences, college of dentistry Qassim university, Saudi Arabia \\ *Corresponding author E-mail: amal.almutiry@qudent.org
}

\begin{abstract}
Background: Edentulism and number of remaining teeth per capita are commonly used as main indicators of dental health status in national surveys.

Objectives: To determine the level of tooth loss and the most common arch affected, to find the out awareness level of replacement of missing teeth with different prosthetic types and to evaluate the correlation between educational level and tooth loss.

Subjects and methods: This was cross-sectional clinical examination, and questionnaire based study, examining the prosthetic status of young females and their level of awareness to replace missing teeth. Using the sample size calculator with the confidence interval of $95 \%$ and significance of $\mathrm{p}<0.05$, the sample size was calculated to be 200 . The inclusion criteria were female patients visiting Qassim Dental Clinics and primary health care centers, aged between 19-39 years. Data was processed and analyzed through SPSS.

Results: The incidences of partial edentulism were $62.5 \%$ and the highest level of missing teeth was found among young females who have college and postgraduate degree, which was $52.8 \%$. The restored cases were only $16 \%$ out of the affected cases. There was a lack of awareness $39.2 \%$ to restore missing teeth among study population. The most important cause of loss teeth among the studied population of young females of Qassim was caries $90.4 \%$.

Conclusion: The study revealed that young females were concerned about their esthetics than other functions of the masticatory system. This can also be supported with the fact that missing mandible posterior teeth were found to be the most common amongst them. Present study showed that awareness level and motivation were significantly low to restore missing teeth. It also revealed that educational status was not the only predictor of health outcomes.
\end{abstract}

Keywords: Age; Sex; Tooth Loss; Partial Edentulism; Prosthatic Status

\section{Introduction}

Partial edentulousness in a dental arch occurs when one or more but not all natural teeth are lost. The loss of many teeth often reduces the quality of life and has a negative impact on the functional, social and psychological well being of an individual. Generally, it occurs by dental caries and periodontal disease, although other causes include orthodontic or prosthetic treatment needs, impactions, supernumerary teeth, neoplastic, cystic lesions and traumatic injuries (Armour BS et al . 2008) [1]. Missing tooth is known to have an important role in the loss of esthetics, mastication. It may also be a reflection of the success of various preventive, and treatment modalities put in place by the health care delivery system. Partial edentulism leads to several drawbacks to the subjects, including clinical challenges and lifestyle compromises (A. Sheiham and J. Steele, 2001) [2]. Clinically, long-term partial edentulism leads to various undesirable consequences like occlusal discrepancies, esthetic impairment, migration, spacing of surrounding teeth, supra eruption, loss of space, residual ridge resorption and temporomandibular disorders. On the lifestyle compromises, partial edentulism restricts dietary options due to impaired masticatory function, an unhealthy diet lead to wight loss, social disability due to lack of confidence and confined, and poor oral health quality of life (Elham Emami et al.2013) [3]. In 1997, the World Health Organization (WHO) found out that adult should have a minimum of 21 functional teeth to provide the ability to experience a good dietary intake without the need for dentures (WHO, 1997) [4].A 1997)[4]. A partially edentulous patient seeks care for functional reasons when they notice an impaired function to a level that is unacceptable to them. The level at which a patient finds the function to be unacceptable varies based on their perception to oral health. Edentulism and number of remaining teeth per capita are commonly used as main indicators of dental health status in national surveys. There is little documentation regarding the pattern of tooth loss among the young adult population living in Saudi Arabia, especially in Qassim. Recording the prevalence and pattern of partial edentulism it is very important for identifying the prosthetic needs of a community as well as aiding the provision of educational and preventive materials suitable for this population (Lana A. Shinawi, 2012) [5]. In 1995, the earliest survey on a selected population attending the dental school at King Saud University (KSU) Riyadh, Saudi Arabia found out mandibular first molar to be the most frequently missing tooth with a tendency for higher tooth loss in females when compared to males. Missing anteriors and premolars in the maxilla was found to be more frequent than the mandible in which loss of molars was more prevalent (Idowu AT.Al-Shamrani SM, 1995)[6]. Various epidemiologic studies in Saudi-Arabian population showed a high level of awareness and knowledge about dental health and disease conditions amongst male subjects when compared to female subjects (Almas K et al. 2000) [7]. Studies on increasing prevalence of 
partial edentulism among young women of Qassim Saudi Arabia are scarce and hence this study aims in comparing the prosthetic status of young females with their level of awareness to replace missing teeth. The result of this study will provide an insight to the condition of dental health and prosthetic status of the young females attending Qassim university dental clinics and primary health care centers in Buraidah. On other hand, decision-makers and health planners in Qassim need information about risk factors for early tooth loss to help identify individuals at risk so as to establish effective health education programs in different regions.

\section{Material and methods}

This was cross-sectional clinical examination, and questionnaire based study, examining the prosthetic status of young females and their level of awareness to replace missing teeth. Using the sample size calculator with the confidence interval of $95 \%$ and significance of $\mathrm{p}<0.05$, the sample size was calculated to be 200. Data collection was planned to continue for 2 months with a minimum sample size goal of 200 subjects. The inclusion criteria were fe- male patients visiting Qassim dental clinics and primary health care center, aged between 19-39 years. The exclusion criteria were patients with missing third molar, complete edentulism, and patients with premolar extracted for the orthodontic purpose. Data was collected using structured questionnaire method and clinical examination. Before the start of the study, participants were informed about the aim and objectives of study, and informed consents were taken before data collection. Subjects were informed that the data will be anonymous and confidential and the Research Ethical Committee of College of Dentistry, Qassim University, approved the study. The questionnaire consisted of two parts: The first part included information on the individual gender, age, career and occupational status, number of missing teeth, cause and duration of loss teeth, medical history, brushing habits and the second part was the clinical examination form (number of missing teeth, prosthetic status and need).The relationships between the variables were investigated and then evaluated.

Statical analysis: Data presented in frequency distribution and percentages using SPSS11.5.

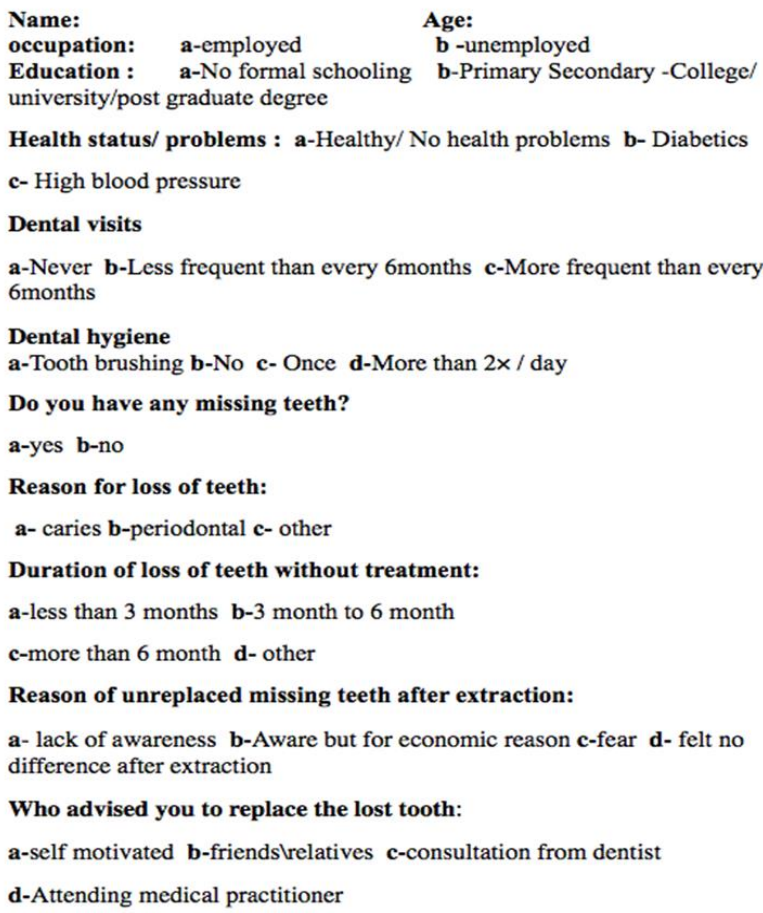

Teeth Missing:

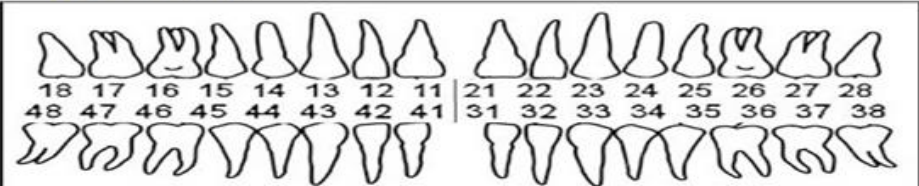

Restored teeth status:

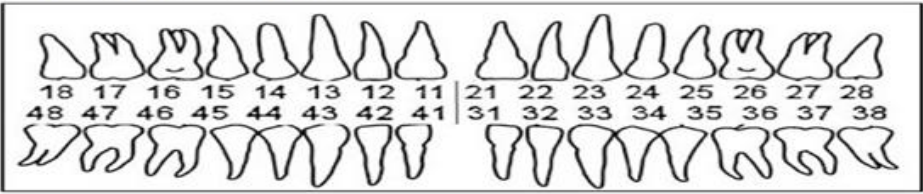

Fig. 1: Survey Questionnaire. 


\section{Results}

The data were collected from 200 Saudi female patients aged from 19 to39 years who reported to the Qassim University Dental Clinics and primary health care centers in Buraidah, Saudi Arabia.

Table 1: Age distribution

\begin{tabular}{lll}
\multicolumn{3}{c}{ Table 1: Age distribution } \\
\hline Age & Frequency & Percentage \\
\hline 19 & 16 & 8 \\
20 & 6 & 3 \\
21 & 8 & 4 \\
22 & 7 & 3.5 \\
23 & 25 & 12.5 \\
24 & 9 & 4.5 \\
25 & 5 & 2.5 \\
26 & 9 & 4.5 \\
27 & 9 & 4.5 \\
28 & 5 & 2.5 \\
29 & 8 & 4 \\
30 & 12 & 6 \\
31 & 9 & 4.5 \\
32 & 8 & 4 \\
33 & 3 & 1.5 \\
34 & 2 & 1 \\
35 & 8 & 4 \\
36 & 8 & 4 \\
37 & 7 & 3.5 \\
38 & 7 & 3.5 \\
39 & 32 & 16 \\
\hline
\end{tabular}

Table 2: Frequency of Partial Edentulism among the Young Females

\begin{tabular}{llll}
\hline $\begin{array}{l}\text { Dental health } \\
\text { status }\end{array}$ & Frequency & Percentage & $\begin{array}{l}95 \% \text { confidence } \\
\text { interval }\end{array}$ \\
\hline $\begin{array}{l}\text { Females with } \\
\text { missing tooth }\end{array}$ & 125 & 62.5 & $(56-69.5)$ \\
$\begin{array}{l}\text { Females with } \\
\text { no missing } \\
\text { tooth }\end{array}$ & 75 & 37.5 & $(30.5-44)$ \\
\hline
\end{tabular}

A total of 125 affected cases were found. $62.5 \%$ of the surveyed groups were affected.

Table 3: Total Number of Treated and Untreated Cases from the Affected Population

\begin{tabular}{lll}
\hline Prosthetic status & Frequency & Percentage \\
\hline Treated & 20 & 16 \\
Untreated & 105 & 84 \\
\hline
\end{tabular}

$84 \%$ in the total affected population had not under gone treatment, the table also shows that $16 \%$ of female had under gone treatment.

Table 4: Most Affected Arch and Most Extracted Tooth

\begin{tabular}{lll}
\multicolumn{3}{c}{ Table 4: Most Affected Arch and Most Extracted Tooth } \\
\hline Arch & Frequency & Percentage \\
\hline Maxillary anterior & 12 & 6 \\
Maxillary posterior & 75 & 37.5 \\
Mandible anterior & 14 & 7 \\
Mandible posterior & 90 & 45 \\
\hline
\end{tabular}

When compared between maxilla and mandible, the maxillary posteriors $45 \%$ were the most extracted teeth. While maxillary anteriors were the least extracted teeth $6 \%$.

Table 5: Ratio of Removable Partial Denture to Fixed Partial Denture among the Restored Cases

\begin{tabular}{lll}
\hline Category & Frequency & Percentage \\
\hline FPD & 18 & 14.4 \\
RPD & 1 & 0.8 \\
Both RPD and FPD & 1 & 0.8 \\
\hline
\end{tabular}

Most of the subjects $14.4 \%$ were treated by fixed partial dentures.
Table 6: Various Reasons for Not Restoring the Edentulous Condition

\begin{tabular}{llll}
$\begin{array}{l}\text { Reason for } \\
\text { not restoring }\end{array}$ & Frequency & Percentage & $\begin{array}{l}95 \% \text { confi- } \\
\text { dence interval }\end{array}$ \\
\hline $\begin{array}{l}\text { Lack of } \\
\text { awareness }\end{array}$ & 49 & 39.2 & $(19-30.5)$ \\
$\begin{array}{l}\text { Economic } \\
\text { Fear }\end{array}$ & 29 & 23.2 & $(9.5-20)$ \\
$\begin{array}{l}\text { Felt no differ- } \\
\text { ence }\end{array}$ & 22 & 17.6 & $(6.5-15.5)$ \\
\hline
\end{tabular}

"Lack of awareness" $39.2 \%$ ranked the highest, $18.4 \%$ felt no difference after extraction, $17.6 \%$ had fear for dental treatment procedures and $23.2 \%$ did not seek any treatment due to financial reasons.

Table 7: Comparing the Level of Education with the Pattern of Tooth Loss

\begin{tabular}{lllll}
\hline $\begin{array}{l}\text { Level of } \\
\text { Education }\end{array}$ & $\begin{array}{l}\text { Has } \\
\text { missing } \\
\text { teeth }\end{array}$ & Percentage & $\begin{array}{l}\text { Has no } \\
\text { missing } \\
\text { teeth }\end{array}$ & Percentage \\
\hline $\begin{array}{l}\text { No formal } \\
\text { schooling }\end{array}$ & 7 & 5.6 & 2 & 2.6 \\
$\begin{array}{l}\text { Primary/ } \\
\text { Secondary } \\
\text { school }\end{array}$ & 52 & 41.6 & 27 & 36 \\
$\begin{array}{l}\text { College/ } \\
\text { Postgraduate }\end{array}$ & 66 & 52.8 & 46 & 61.3 \\
\hline
\end{tabular}

Most of the partially edentulous females have college and postgraduate degree $52.8 \%$.

Table 8: The Most Important Cause of Loosing Teeth

\begin{tabular}{llll}
\hline $\begin{array}{l}\text { Cause of loss } \\
\text { teeth }\end{array}$ & Frequency & Percentage & $\begin{array}{l}95 \% \text { confidence } \\
\text { interval }\end{array}$ \\
\hline Caries & 113 & 90.4 & $(50-64)$ \\
Periodontal & 8 & 6.4 & $(1.5-7)$ \\
Other & 4 & 3.2 & $(.0-3.5)$ \\
\hline
\end{tabular}

Caries ranked most frequent $90.4 \%$ cause of tooth loss of all the affected cases while periodontal problem was second most frequent cause $6.4 \%$.

\section{Discussion}

Edentulism is an imminent problem throughout the world population. The pattern of partial edentulism has been assessed in many selected populations in different countries. It is an irreversible condition that can lead to functional impairment, physical, psychological, and social problems. Several researchers have analysed the correlation between partial edentulism and its influencing factors as socio-economic parameters, age, gender, education level, etc. The researches on tooth loss have been limited primarily to cross-sectional studies of subnational groups that estimate the prevalence of complete edentulism, and the mean number of teeth lost (Muneeb A 2013, Zaigham AM and Muneer MU 2010, Abdel-Rahman HK 2013) [8], [9], [10]. Shinawi conducts a survey for five years from 2004 and 2009 on the prevalence and pattern of tooth loss in a sample of patients attending King AbdulAziz University and reported detailed patterns of tooth loss in the selected sample of patients receiving dental treatment at the faculty of dentistry in Jeddah, Saudi Arabia. The most common pattern of partial edentulism was Kennedy Class III, and definitive partial denture was the first choice for treatment with a removable prosthesis (Lana A. Shinawi, 2012 [5]. Dolan et al. conducted a study about risk indicators of edentulism, partial tooth loss and prosthetic status among black and white middle-aged and older adults through interview and dental examination. He found out that the black people were less likely to receive prosthetic crowns and people who had poor general health was significantly associated with edentulism (Dolan TA et al. 2001) [11]. GB Goutham et al. conducted to assess the sociodemographic factors and partial edentulism and concluded that prevalence of partial edentulism 
among study population was high. In addition, prevalence of partial edentulism is more common in mandibular jaw than maxillary jaw (Goutham GB et al .2016) [12]. Ashish Dewangan et al. conducted a study to correlate the prevalence of various Kennedy's classes of partially edentulous conditions with the pattern of tooth loss in the patients attending the Department of Prosthodontics, Crown and bridge and concluded that the most common class of partial edentulousness in the studied subjects irrespective of age and sex was Kennedy's class III. The incidence of partial edentulism in the mandible was more common than partial edentulism in the maxilla. The maximum incidence of Class III was encountered in age group lying between 18-30 years (Dewangan A and Deeplaxmi, 2016) [13]. Yasser A. Araby et al. conducted a study to find the patterns of partial edentulism among a selected Saudi population and to correlate the pattern of partial edentulism with age and gender and concluded that Kennedy's Class III was the most commonly encountered pattern of partial edentulism in both upper and lower arches and Kennedy's Class IV was the least common pattern. With age, an increase in the tendency to Class I \& Class II and a decrease in Class III was shown with a statistical significant difference between the different age groups, on the other hand, there was no statistical significant difference between both genders (Yasser A. Araby et al . 2017). Our study analyzed the prevalence of partial edentulism among young Saudi women of Qassim. Saudi Arabia aged (19-39) years and their perception of early tooth loss. The level of awareness of young adult to restore their missing teeth also assessed. V. T. Abdurahiman examined student aged 18-25 years from tirur taluk, malappuram district, kerala and found out that the frequency of partial edentulism among the surveyed group was significant with predominance in maxillary posterior edentulousness in men and mandibular posterior edentulousness in women. All restored cases were with fixed bridges, and no anterior edentulousness was found (Abdurahiman VT et al, 2013) [15]. The study also, revealed a lack of awareness and needs to educate the population, which is in line with the results of the present study. In the examined population, the incidence of partial edentulism was $125(62.5 \%)$ (Table2), which indicates that there was very highly significant difference in young female patients having been missing teeth, which is consistent with a study done by Sapkota b et al. Who observed that females were more edentulous compared to males but at the same time, they show a higher level of replacement of missing teeth (Sapkota $\mathrm{B}$ et al. 2013) [16]. This may be due to their dependency upon the males for their dental treatment to save the teeth. However, they are more conscious about their appearance, which explains their preference for replacement of missing teeth. Patel JY et al. observed that women show greater amount of edentulousness than males (Patel JY et al. 2014) [17]. And in our study, the highest level of missing teeth was found among females who have college and postgraduate degree, which was $66(52.8 \%)$. Reddy ns et al. found that less less educated aren't much aware about oral health care. People with better employment status are more concerned about their aesthetics and opted for dental treatment (Reddy NS et al. 2012) [18] which not in the line with our study. Socio economic parameters have direct influence on the replacement of missing teeth.

In the present study, the restored cases were only 20 (16\%) (Table 3 ) out of the affected cases. The most important reasons for not restoring the missing teeth might be highlighted using (Table 6). It also shows the various reasons and percentages for not restoring the condition, out of which the option "lack of awareness", showed the highest percentage $49(32.2 \%)$, which showed that there was a lack of awareness to restore missing teeth among study population. Other reasons for not restoring missing teeth economic $(23.2 \%)$, fear (17.6\%),felt no difference(18.4\%). Prabu $\mathrm{n}$ et al. have found that the lack of motivation was the common reason for not seeking dental treatment (Prabhu $\mathrm{N}$ et al .2009) [19]

The most important causes of loss teeth among the young females were caries $(90.4 \%)$, periodontal problems $(6.4 \%)$. WHO reported that by age of 34 years, teeth were mostly lost due to caries, and after age 34 years the cause is in most cases periodontal disease. However, it is difficult to establish the validity of reasons for tooth extraction, because this relies on the accuracy of subjective information provided by everyone (WHO, 1978) [20].

It can be concluded from the above findings that, the young female patients might be more concerned about their esthetics than other functions of the masticatory system. This can also be supported with the fact that missing mandible posterior teeth was found to be the most common among the young females while missing maxillary anteriors were the least common which is in the line with results of the other studies (Manji F et al.1988, Kida IA et al .2006) [21], [22], molars accounted for the majority of missing teeth. (Table 4) this is because the morphology of these teeth is conducive to harboring caries producing bacteria. These clearly identify that there is a strong need to educate the young generation. Most restored female patients preferred fixed dentures than the removable ones (table 5).

\section{Conclusion}

In the present study, there was very high percentage of young female patients having missing teeth, and the highest level of missing teeth was found among females who have college and postgraduate degree. It is important to point out that both Saudi and non-Saudi patients receive free dental treatment at QUDC including prosthetic RPD and FPD and results reported in the present survey is not affected by patients socio economic limitations. Missing mandible posterior teeth was found to be the most common among the young females while missing maxillary anterior was the least common. This study showed poor knowledge of consequences of missing teeth among the subjects studied. Present study showed that awareness level and motivation was significantly low to restore missing teeth. It also revealed that educational status is not the only predictor of health outcomes. Young women of Qassim are in need of education regarding the possible impact of caries and periodontitis on partial edentulism, prevention and treatment options. Hence effective continuous education programs focusing on the oral health needs focusing on the community especially women should be carefully planned.

\section{References}

[1] Armour BS, Swanson M, Waldman HB, Perlman SP (2008), A profile of state-level differences in the oral health of people with and without disabilities, in the U.S., in 2004. Public Health Reports 123, pp.67-75. https://doi.org/10.1177/003335490812300110.

[2] A. Sheiham and J. Steele (2001), Does the condition of the mouth and teeth affect the ability to eat certain foods, nutrient and dietary intake and nutritional status amongst older people?", Public Health $\begin{array}{llll}\text { Nutrition, vol. } & 4, & \text { pp. } & \text { 797-803. }\end{array}$ https://doi.org/10.1079/PHN2000116.

[3] Elham Emami, Raphael Freitas de Souza, Marla Kabawat, Jocelyne S. Feine (2013), The Impact of Edentulism on Oral and General Health. International Journal of Dentistry, Volume 2013 .pp .1-7. https://doi.org/10.1155/2013/498305.

[4] World Health Organization, Oral Health Surveys: Basic Methods, World Health Organization, Geneva, Switzerland, 4th edition, 1997.

[5] Lana A. Shinawi (2012), Partial edentulism: a five-year survey on the prevalence and pattern of tooth loss in a sample of patients attending King AbdulAziz University - Faculty of Dentistry, Life Science Journal 9.pp 2665-2671

[6] Idowu AT.Al-Shamrani SM (1995). Pattern of tooth loss in a selected population at King Saud University College of Dentistry, The Saudi Dental Journal 7.pp .135-140.

[7] Almas K, Albaker A, Felembam N (2000), Knowledge of denta health and diseases among dental patients, a multicentre study in Saudi Arabia, Indian Journal of Dental Research11.pp.145-155.

[8] Muneeb A (2013), Causes and pattern of partial edentulism/ exodontia and its association with age and gender: semi-rural population, Baqai Dental College, Karachi, Pakistan. International dental journal of student research1.pp13-18. 
[9] Zaigham AM, Muneer MU (2010), Pattern of partial edentulism and its association with age and gender, Pakistan Oral and Dental Journal 30.pp.260-63.

[10] Abdel-Rahman HK, Tahir CD, Saleh MM (2013), Incidence of Partial edentulism and its relation with age and gender, Zanco Journal of Medical Sciences17.pp.463-470. https://doi.org/10.15218/zjms.2013.0033.

[11] Dolan TA, Gilbert GH, Duncan RP, Foerster U (2001),Risk indicators of edentulism,partial tooth loss and prosthetic status among black and white middle-aged and older adults, Community Dentistry and Oral Epidemiology 29.pp. 329-340. https://doi.org/10.1111/j.1600-0528.2001.290502.x.

[12] Goutham GB, Shrivastava N, Mathew S, Alani MM, Reba PB, Bulusu A(2016),Sociodemographic Factors and Partial Edentulism: An Exploratory Study, International Journal of Oral Care \& Research 4 . Pp.276-279. https://doi.org/10.5005/jp-journals-100510062 .

[13] Dewangan A, Deeplaxmi(2016), Correlation of prevalence of various kennedy's classes of partially edentulous conditions with the pattern of tooth loss - A cross sectional study, Journal of Advanced Medical and Dental Sciences Research 4 .pp.174-179. https://doi.org/10.21276/jamdsr.2016.4.4.36.

[14] Yasser A. Araby, Abdurrahman S. Almutairy, and Fawaz M. Alotaibi (2017), Pattern of Partial Edentulism in Correlation to Age and Gender among a Selected Saudi Population, International Journal of Dental Sciences and Research 5. Pp.1-4.

[15] Abdurahiman VT, Kahdar MA, Jolly SJ (2013), Frequency of partial edentulism and awareness to restore the same: A Cross sectional study in the age group of 18-25 years among Kerala student population, Journal of Indian Prosthodontic Society 13. Pp.461-65. https://doi.org/10.1007/s13191-012-0246-2.

[16] Sapkota B, Adhikari B, Upadhaya C (2013).A Study of Assessment of Partial edentulous patients based on Kennedy's classification at Dhulikhel Hospital Kathmandu University Hospital. Kathmandu University Medical Journal 44.pp.325-27

[17] Patel JY, Vohra MY, Hussain JM (2014), Assessment of Partially edentulous patients based on Kennedy's classification and its relation with Gender Predilection. International Journal of Scientific Study 2.pp. 32-36.

[18] Reddy NS, Reddy NA, Narendra R, Reddy SD (2012), Epidemiological survey on edentulousness. The Journal of Contemporary Dental Practice 13.pp562-70. https://doi.org/10.5005/jp-journals10024-1187.

[19] Prabhu N, Kumar S, D'souza M, Hegde V (2009), Partial Edentulousness in a rural population based on Kennedy's classification: An Epidemiological study, Journal of Indian Prosthodontic Society 9.pp.18-23. https://doi.org/10.4103/0972-4052.52869.

[20] WHO Epidemiology, etiology \& prevention of periodontal disease. World Health Organ Tech Rep Ser NO. 621. Geneva: WHO, 1978.

[21] Manji F, Baelum V, Fejerskov O (1988), Tooth mortality in an adult rural population in Kenya, Journal of Dental Research 67,pp. 496-500. https://doi.org/10.1177/00220345880670021301.

[22] Kida IA, Astray AN, Strand GV, Masalu JR (2006), Clinical and socio-behavioral correlates of tooth loss: a study of older adults in Tanzania. BMC Oral Health 6. pp 1-10. https://doi.org/10.1186/1472-6831-6-5. 